\title{
Infections with human coronaviruses NL63 and OC43 among hospitalised and outpatient individuals in São Paulo, Brazil
}

\author{
Tatiane Karen Cabeça ${ }^{1 /+}$, Emerson Carraro' ${ }^{1}$, Aripuanã Watanabe ${ }^{1}$, Celso Granato ${ }^{1}$, Nancy Bellei ${ }^{1}$ \\ 'Disciplina de Infectologia, Laboratório de Virologia Clínica, Departamento de Medicina, \\ Universidade Federal de São Paulo, São Paulo, SP, Brasil
}

\begin{abstract}
The incidence and clinical features of human coronaviruses (HCoVs) among Brazilian patients with respiratory illness are not well known. We investigated the prevalence of HCoVs among Brazilian outpatients and hospitalised patients with respiratory illnesses during 2009 and 2010. To identify the HCoVs, pancoronavirus and species-specific reverse-transcriptase polymerase chain reaction assays were performed. Five of 394 samples were positive for HCoVs (1.2\%): 1/182 (0.5\%) outpatients and 4/212 (1.8\%) hospitalised patients. The OC43 and NL63 HCoVs were identified. Two patients were admitted to the intensive care unit. Underlying chronic disease was reported in cases and one diabetic adult died. HCoVs can cause lower respiratory infections and hospitalisation. Patients with preexisting conditions and respiratory infections should be evaluated for HCoV infections.
\end{abstract}

Key words: human coronavirus OC43 - human coronavirus NL63 - respiratory tract infections

Five human coronaviruses (HCoVs) have been identified to date. $\mathrm{HCoV}-\mathrm{OC} 43$ and $\mathrm{HCoV}-229 \mathrm{E}$ were first identified in the mid-1960s (Hamre \& Procknow 1966) and were subsequently found to cause the common cold. These viruses were the only coronaviruses identified in humans until 2003, when $\mathrm{HCoVs}$ received worldwide attention with the emergence of severe acute respiratory syndrome (SARS), which is caused by a novel coronavirus (SARS-CoV). The increased research on these viruses led to the discovery of two additional HCoVs: HCoV-NL63 in the Netherlands and HCoV-HKU1 in China (van der Hoek et al. 2004, Woo et al. 2005). $\mathrm{HCoVs}$ cause upper respiratory tract illness and occasionally cause lower respiratory tract disease in susceptible individuals. The incidence and clinical features of $\mathrm{HCoV}$ infections in Brazilian patients with respiratory illness is not well known, especially among adults. There are few studies that describe $\mathrm{HCoV}$ infections among adults (Bellei et al. 2008, Gaunt et al. 2010). The aim of the present study was to investigate the occurrence of HCoVs among Brazilian outpatients and hospitalised patients who received care at the Hospital of São Paulo Federal University, Brazil, during 2009 and 2010. A total of 394 samples were collected with nasopharyngeal swabs. The final pool of subjects included 182 outpatient children from the general community and 212 hospitalised patients; of these 212 patients, 136 were children and 76 were adults. Assays to identify $\mathrm{HCoVs}$ in patients were performed using a two-step process. First, an initial pancoronavirus reverse-transcription polymerase chain reaction (RT-PCR) screening assay was performed (Vijgen et al. 2008). Second, species-specific RT-PCR as-

+ Corresponding author: taticabeca@yahoo.com.br

Received 20 October 2011

Accepted 11 January 2012 says were used to identify the specific $\mathrm{HCoV}$ species (Dare et al. 2007). Amplicons were further characterised by sequencing. Epidemiological and clinical data from outpatients were obtained using a standardised questionnaire and data from hospitalised patients were obtained from medical charts. The pancoronavirus assay detected five/394 (1.2\%) coronavirus-positive samples. Within the outpatient group, which was comprised only children, one/182 (0.5\%) patients was positive. Within the hospitalised patient group, four/212 (1.8\%) patients were positive: two/136 were children (1.4\%) and two/76 were adults $(2.6 \%)$. $\mathrm{HCoV}-\mathrm{OC} 43$ was documented in two samples from hospitalised patients, one of which was a nosocomial infection; three HCoV-NL63 positive samples were identified, one of which was obtained from an outpatient and two of which were obtained from hospitalised patients. Sequencing confirmed the specificity of the species-specific RT-PCR assays. Coronavirus infections occurred during the spring, autumn and winter and more coronavirus-infected cases were documented in 2010 than in 2009. The median age of HCoV-infected patients was seven years (ranging from 11 months to 46 years). Eighty percent (4/5) of infected patients reported several underlying conditions, but no chronic lung disease was reported (Table). Fever and cough were the most common symptoms at presentation. Dyspnea was reported in two cases and bronchospasm was only reported in the three HCoV-NL63 cases. Three patients presented with lower respiratory tract infections. Two of the hospitalised patients were further admitted to the intensive care unit during their hospital stay. Eight days was the median length of the hospital stay for hospitalised coronavirus-infected patients (ranging from 5-30 days). $\mathrm{HCoV}-\mathrm{OC} 43$-infected patients had longer hospital stays than HCoV-NL63-infected patients. Three of the four hospitalised patients had good outcomes, but the diabetic adult died of HCoV-NL63-associated pneumonia nine days after admission. The present study is the first Brazilian report of $\mathrm{HCoV}$ infections in outpatients 
TABLE

Demographic and clinical data of coronavirus-infected patients during 2009-2010

\begin{tabular}{|c|c|c|c|c|c|}
\hline & \multicolumn{5}{|c|}{ Patients } \\
\hline & 1 & 2 & 3 & 4 & 5 \\
\hline \multicolumn{6}{|l|}{ Characteristics } \\
\hline $\mathrm{HCoV}$ species & $\mathrm{HCoV}-\mathrm{OC} 43$ & HCoV-NL63 & $\mathrm{HCoV}-\mathrm{OC} 43$ & HCoV-NL63 & HCoV-NL63 \\
\hline Sample date & September/09 & May/10 & April/10 & June/10 & June/10 \\
\hline Age & 2 years & 5 years & 43 years & 46 years & 11 months \\
\hline Gender & Female & Female & Male & Female & Female \\
\hline Underlying & Megacolon & None & HIV & Diabetes & Liver \\
\hline Disease & Prematurity & - & - & Mellitus & Transplant \\
\hline History of smoking & - & - & + & + & - \\
\hline \multicolumn{6}{|l|}{ Clinical features } \\
\hline Fever & + & + & + & + & + \\
\hline Cough & + & + & + & + & + \\
\hline Myalgia & - & + & + & + & - \\
\hline Headache & - & - & + & - & - \\
\hline Diarrhoea & - & - & - & + & - \\
\hline Rhinorrhoea & - & + & - & + & - \\
\hline Sore throat & - & - & - & + & - \\
\hline Bronchospasm & - & - & - & + & - \\
\hline Dyspnea & - & - & + & + & - \\
\hline LRTI & + & - & + & + & - \\
\hline Hospitalization & + & - & + & + & + \\
\hline Outcome & Survived & Survived & Survived & Died & Survived \\
\hline
\end{tabular}

HCoV: human coronaviruses; LRTI: lower respiratory tract illness; HIV: human immunodeficiency virus infected; +: present; -: absent.

and hospitalised patients to describe NL63 infection in an adult patient. Because the subjects of our study included both outpatients and hospitalised patients, the majority of the patients included in this study were believed to have a common cold. The composition of our subject pool could be a limitation of our study and might explain the small number of coronavirus-positive cases. Gaunt et al. (2010) detected $0.3-0.85 \%$ coronavirus-positive samples across all ages and we hypothesised that the H1N1 2009 influenza pandemic wave might have influenced the dynamics of the other respiratory viruses, mainly in 2009. The coronavirus-positive rate found among adults revealed that HCoVs may be representative causal agents of respiratory disease among adults as well as children. This study is one of the few studies to record a fatal case of HCoV-NL63 infection (Bastien et al. 2005, Cabeça \& Bellei 2012). In conclusion, our data demonstrate that $\mathrm{HCoVs}$ can cause more than just the common cold and mild respiratory tract disease. Therefore, at-risk patients presenting with severe respiratory infections should be evaluated for $\mathrm{HCoV}$ infections. According to the data presented herein, the NL63 HCoV represents an important pathogen that is involved in unexplained respiratory illnesses.

\section{REFERENCES}

Bastien N, Anderson K, Hart L, Van Caeseele P, Brandt K, Milley D, Hatchette T, Weiss EC, Li Y 2005. Human coronavirus NL63 infection in Canada. J Infect Dis 191: 503-506.
Bellei N, Carraro E, Perosa A, Watanabe A, Arruda E, Granato C 2008. Acute respiratory infection and Influenza-like illness viral etiologies in Brazilian adults. J Med Virol 80: 1824-1827.

Cabeça TK, Bellei N 2012. Human coronavirus NL-63 infection in a Brazilian patient suspected of H1N1 2009 influenza infection: description of a fatal case. J Clin Virol 53: 82-84.

Dare RK, Fry AM, Chittaganpitch M, Sawanpanyalert P, Olsen SJ, Erdman DD 2007. Human coronavirus infections in rural Thailand: a comprehensive study using real-time reverse-transcription polymerase chain reaction assays. J Infect Dis 196: 1321-1328.

Gaunt ER, Hardie A, Claas EC, Simmonds P, Templeton KE 2010. Epidemiology and clinical presentations of the four human coronaviruses 229E, HKU1, NL63 and OC43 detected over 3 years using a novel multiplex real-time PCR method. J Clin Microbiol 48: 2940-2947.

Hamre D, Procknow JJ 1966. A new virus isolated from the human respiratory tract. Proc Soc Exp Biol Med 121: 190-193.

van der Hoek L, Pyrc K, Jebbink MF, Vermeulen-Oost W, Berkhout RJ, Wolthers KC, Wertheim-van Dillen PM, Kaandorp J, Spaargaren J, Berkhout B 2004. Identification of a new human coronavirus. Nat Med 10: 368-373.

Vijgen L, Moës E, Keyaerts E, Li S, Van Ranst M 2008. A pancoronavirus RT-PCR assay for detection of all known coronaviruses. Methods. Mol Biol 454: 3-12.

Woo PC, Lau SK, Chu CM, Chan KH, Tsoi HW, Huang Y, Wong BH, Poon RW, Cai JJ, Luk WK, Poon LL, Wong SS, Guan Y, Peiris JS, Yuen KY 2005. Characterization and complete genome sequence of a novel coronavirus, coronavirus HKU1, from patients with pneumonia. J Virol 79: 884-895. 